\title{
Mouse (Mus musculus) embryonic cerebral cortex cell death caused by carbofuran insecticide exposure
}

\author{
Epy Muhammad Luqman ${ }^{1,2}$, I Ketut Sudiana ${ }^{3}$, Win Darmanto ${ }^{4}$, \\ Agung Budianto Achmad ${ }^{5}$, Widjiati ${ }^{2}$ \\ ${ }^{1}$ Postgraduate School, ${ }^{5}$ Department of Health, Faculty of Vocational Studies, \\ Universitas Airlangga Surabaya, 60286, Surabaya, Indonesia \\ ${ }^{2}$ Department of Veterinary Anatomy, Faculty of Veterinary Medicine, \\ ${ }^{4}$ Department of Biology, Faculty of Science and Technology, \\ Universitas Airlangga, 60115, Surabaya, Indonesia \\ ${ }^{3}$ Department of Anatomical Pathology, Faculty of Medicine, \\ Universitas Airlangga Surabaya, 60131, Surabaya, Indonesia \\ epy-m-1@fkh.unair.ac.id
}

Received: December 21, 2018

Accepted: July 2, 2019

\begin{abstract}
Introduction: The aim of the study was to describe the process of neuron death in the cerebral cortex caused by embryonic carbofuran exposure. Material and Methods: 81 mouse foetuses from 27 breeding mice were used in the study. Carbofuran was administered by gavage from the $6^{\text {th }}$ to the $15^{\text {th }}$ day of gestation to two groups: one at 0.0208 and the other at $0.0417 \mathrm{mg} / \mathrm{kg} \mathrm{b} . \mathrm{w}$. On the $17^{\text {th }}$ day, the mice were sacrificed and the foetuses were taken to measure the ROS (malondialdehyde/MDA and superoxide dismutase/SOD) activity in brain tissue, the number of apoptotic embryonic cerebral cortex neurons using a TUNEL assay, and necrotic cells using HE staining. Examination of p53 and caspase 3 expression was done by immunohistochemistry. Data were analysed using analysis of variance (ANOVA) and Duncan's test. Results: Increased activity of cerebral ROS characterised by significant elevation of the MDA level $(\mathrm{P}<0.05)$, decreased SOD $(\mathrm{P}<0.01)$, increased $\mathrm{p} 53$ and caspase 3 expression, and cerebral cortical neuron death either by necrosis or apoptosis $(\mathrm{P}<0.05)$ were found. At the low dose carbofuran increased expression of p53, caspase 3, and apoptosis. At the high dose it increased levels of MDA and necrosis. Conclusion: Increased expression of p53 and caspase 3 and apoptosis indicated that carbofuran may cause apoptosis through the intrinsic pathway. The increased apoptosis grants an opportunity to prevent and treat the effect of ROS due to gestational carbofuran exposure.
\end{abstract}

Keywords: mice, carbofuran, ROS, necrosis, apoptosis.

\section{Introduction}

Carbofuran $\left(\mathrm{C}_{12} \mathrm{H}_{15} \mathrm{NO}_{3} ; 2\right.$ 2,3-dihydro-2,2-dimethyl -7-benzofuranol methylcarbamate), commonly known as Furadan, is a broad-spectrum carbamate pesticide which is used in various farm practices in order to increase crop productivity. Food, water, and air contamination with carbofuran $(\mathrm{CF})$ has become a serious concern because of its adverse effects that pose hazards not only to humans, but also animals, wildlife, and fish. CF residue and metabolite substances can be found in water samples collected from rice paddies, vegetable fields, and vulture carcasses (20). In 2001, a flower plantation in Ecuador was contaminated by CF. There were some babies born with impaired reflex and motor functions. During their childhood, the effect of CF contamination was brain development dysfunctions, such as poor concentration and memory (8). CF, a potential environmental xenobiotic, has the ability to cross the blood-brain barrier and to adversely influence brain functions (6). Like organophosphate, $\mathrm{CF}$ ingestion by gavage may cause significant oxidative damage to the cerebral cortex, cerebellum, and brain stem. Cerebral cortex neuron death caused by CF exposure potentially reduces motor function (18).

Pregnant mothers exposed to CF can be treated successfully (the effects are reversible); however, foetuses exposed to CF cannot be treated effectively (the effects are irreversible). Cellular necrosis which is often found in foetal livers, brains, and kidneys is 
proportionate to CF contents in the mother's serum. Two main CF metabolites which cause toxicity and permeate through the placental barrier are 3-hydroxycarbofuran and 3-ketocarbofuran, which cause serious damage to the maternal-placental-foetal unit. The effect of CF on the brain is more severe than the effect on other organs, particularly the liver (14).

Oral and intraperitoneal CF intake have proven to be able to increase reactive oxygen species (ROS) in adult mouse brains and increase the levels of malondialdehyde (MDA) (6). This was paralleled by an increase in MDA level in rat brains (59.38\%) and in the mitochondria (43.7\%) isolated from CF-exposed rat brains $(12,25)$. The increasing ROS may reduce the activity of brain antioxidant enzymes such as superoxide dismutase (SOD) and catalase (CAT) (25, 9). Concomitantly, the activities of superoxide dismutase, catalase, glutathione peroxidase, and glutathione reductase were significantly decreased after CF exposure (11). Reduced catalase activity in responding to $\mathrm{CF}$ induction weakens protection against free radicals, which leads to brain vulnerability to CF oxidative stress. Chromosomal or DNA damage caused by hydroxyl radicals $(\bullet \mathrm{OH})$ activates p53 which in turn stimulates Bax activity. Bax proteins suppress $\mathrm{BCl}-2$ activity on the mitochondrial membrane which changes its permeability. Change on the mitochondrial membrane causes cytochrome $\mathrm{C}$ release to the cytosol. Cytochrome $\mathrm{C}$ activates Apaf-1 followed by the caspase cascade on pro-caspase 9 to process caspase 3 . The activated caspase 3 will in turn activate DNase which permeates the nucleus membrane and destroys DNA, which causes apoptosis (26). CF induces DNA fragmentation, neuron death by apoptosis, and down-regulates the $\alpha 7$ subunit of the nicotinic acetylcholine receptor (nAChRs) (13).

Emerging evidence indicates that oxidative stress plays an important role in CF neurotoxicity after subchronic exposure. Excessive ROS activity may lead to neuron injury and death (6). However, information regarding the effect of brain cell death after CF intoxication (necrosis and apoptosis) on oxidative stress during the embryonic period is lacking. A deeper understanding of the brain cell death mechanism in mouse foetuses due to $\mathrm{CF}$ exposure is necessary to acquire the knowledge resources for basic treatment and prevention during the embryonal period. Besides, it is important to understand this mechanism in order to identify the most sensitive period as well as the type of cells affected by CF exposure during the embryonic period. If the mechanism and the type of dead cells are recognised, actions can be taken to prevent the degeneration of reflexes and motor skills in infant mice. The aim of this research was to determine the brain cell death mechanism in mouse foetuses the mothers of which were exposed to $\mathrm{CF}$ during the embryonal period. This was achieved by measuring the MDA and SOD levels as an indicator of ROS production, apoptosis pathway (p53 and caspase 3), and necrosis of cerebral cells.

\section{Material and Methods}

Material and instruments. The materials used in this research consisted of carbofuran (Furadan 3GR, PT. Bina Guna Kimia MDL, Indonesia) and chicken feed CP 593 (PT Charoen Pokhphand, Indonesia). The equipment used in MDA content measurement were reaction flasks $(5 \mathrm{~mL})$ and a model $6 / 20$ Coleman Junior II spectrophotometer (Perkin-Elmer, USA). This research was conducted in the Department of Veterinary Anatomy in the Faculty of Veterinary Medicine at Universitas Airlangga Surabaya, and the Central Laboratory of Biology at Universitas Brawijaya Malang, Indonesia.

Experimental animals. In this research 27 tenweek-old female mice (Mus musculus) were used and they were divided into three experimental groups with nine specimens in each. The groups consisted of mice injected with saline as controls, mice given $\mathrm{CF}$ at a low dose, and mice administered a higher dose.

Mice which had been adapted for seven days were injected with pregnant mare serum gonadotropin (PMSG) at a dose of $5 \mathrm{IU} / \mathrm{mouse}$ followed two days later by a human chorionic gonadotrophin (HCG) injection of $5 \mathrm{IU} /$ mouse. Then they were mated to 14 -week-old male mice with a $1: 1$ ratio of males to females. On day 0 of gestation the presence of a vaginal plug in the vulvae was determined (25). The doses of CF used were 0.0417 $\mathrm{mg} / \mathrm{kg}$ b.w. (1/12 $\mathrm{LD}_{50}$, where $\mathrm{LD}_{50}=0.5 \mathrm{mg} / \mathrm{kg}$ b.w., $\mathrm{n}=9)$ and $0.0208 \mathrm{mg} / \mathrm{kg} \mathrm{b.w.} \mathrm{(1/24} \mathrm{LD} 50, \mathrm{n}=9)$. The control group $(n=9)$ received $0.9 \%$ physiological $\mathrm{NaCl}$. From the $6^{\text {th }}$ to the $15^{\text {th }}$ day of gestation, the mice were exposed to $\mathrm{CF}$ by gavage using a disposable syringe. On the $17^{\text {th }}$ day of gestation, the mice were sacrificed to collect foetal cerebra. Three foetuses were taken from each of the 27 breeding mice for further analysis. Cerebrum ROS activity was measured based on its MDA level, SOD activity, p53 and caspase 3 expressions, and cerebral cortex neuron death (apoptosis and necrosis).

Malondialdehyde (MDA) measurement. MDA was determined by the method of Conti et al. (4). Cerebral cortex MDA content was measured in 17-dayold foetuses by applying malondialdehyde/ thiobarbituric acid reactive substance (MDA/TBARS), namely by mixing one gram of the cerebrum with $9 \mathrm{~mL}$ of PBS using a spatula. The suspension was centrifuged at 3,000 rpm for $15 \mathrm{~min}$. Supernatant $(4 \mathrm{~mL})$ was collected, $1 \mathrm{~mL}$ of $15 \%$ TCA and $0.37 \%$ TBA solution in $0.25 \mathrm{~N} \mathrm{HCl}$ was added, and the resulting solution was heated in a water bath at $80^{\circ} \mathrm{C}$ for $15 \mathrm{~min}$. After being allowed to cool at room temperature for $60 \mathrm{~min}$, the mixture was centrifuged at $3,000 \mathrm{rpm}$ for $15 \mathrm{~min}$. Absorbance value was determined based on existing red area using spectrophotometer with $532 \mathrm{~nm}$ wavelength.

Superoxide dismutase (SOD) activity examination. The SOD activity was measured using a water soluble tetrazolium (WST) SOD assay kit purchased from Sigma-Aldrich (USA). Cerebral tissue was washed using PBS or $150 \mathrm{mM} \mathrm{KCl}$ to remove erythrocytes. The washed tissue was homogenised with 
$0.1 \mathrm{M}$ Tris/ $\mathrm{HCl}$ (pH 7.4) containing $5 \mathrm{mM} \beta-\mathrm{ME}$ of $0.5 \%$ Triton X-100 and $0.1 \mathrm{mg} / \mathrm{mL}$ of phenylmethylsulphonyl fluoride (PMSF). The compound was centrifuged at $14,000 \mathrm{~g}$ at $4^{\circ} \mathrm{C}$ for $5 \mathrm{~min}$. The debris of supernatant was removed to obtain cytolytic and mitochondrial SOD. The examination was conducted by putting $20 \mu \mathrm{L}$ of sample into a sample cuvette and cuvette blank 2 and putting the same with addition of $20 \mu \mathrm{L} \mathrm{H}_{2} \mathrm{O}$ into cuvette blank 1 and cuvette blank 3 . WST working solution in a $200 \mu \mathrm{L}$ volume was added to each cuvette (the sample cuvette and cuvette blanks 1,2, and 3). Dilution buffer $(20 \mu \mathrm{L})$ was added to cuvette blanks 2 and 3 and enzyme working solution $(20 \mu \mathrm{L})$ was added to the sample cuvette and stirred. The cuvettes were incubated at $37^{\circ} \mathrm{C}$ for $20 \mathrm{~min}$. Absorbance was read at the $450 \mathrm{~nm}$ wavelength using a microplate reader. SOD activity was calculated with the formula

$$
\begin{gathered}
\text { SOD activity } \\
\text { inhibition percentage })
\end{gathered}=\frac{\left(A_{\text {blank 1 }}-A_{\text {blank 3 }}\right)-\left(A_{\text {sample }}-A_{\text {blank 2 }}\right)}{\left(A_{\text {blank 1 }}-A_{\text {blank 3 }}\right)} \times 100 \%
$$

Immunohistochemical examination of p53 and caspase 3 expression. Brain tissue of 17-day-old gestated foetuses was fixed in a buffer of $10 \%$ formalin and paraffin and $5 \mu \mathrm{m}$ sections were prepared and placed on slides using polylysine for adherence. The area which was examined was the motor cortex area obtained through coronal sectioning performed at 11/1.56 mm from the frontal lobe (21). The glass slides were cooled down and blocked with $1 \%$ bovine serum albumin (BSA) for an hour and washed twice in PBS (pH 7.4) for 5 min. Slides were labelled with the primary antibodies p53 monoclonal antibody (Santa Cruz Biotechnology, USA) and caspase 3 monoclonal antibody (Santa Cruz Biotechnology) in $1 \%$ BSA overnight at $4{ }^{\circ} \mathrm{C}$. The slides were labelled with biotin secondary antibody label (DakoCytomation, Denmark) in 1:500 composition for an hour at room temperature and washed with PBS ( $\mathrm{pH}$ 7.4). They were next supplemented with strepovidin horseradish peroxidase, 1:500, for $40 \mathrm{~min}$ and washed with PBS ( $\mathrm{pH} 7.4$ ). Then the slides were covered with diaminobenzidine tetrahydrochloride (DAB) chromogen substrate for $20 \mathrm{~min}$, washed with PBS again and washed in distilled water for $5 \mathrm{~min}$ in three repetitions and counterstained.

Apoptosis examination using the TUNEL test. Cell apoptosis examination was conducted by TUNEL assay. A total of $25 \mu \mathrm{g} / \mathrm{mL}$ of proteinase $\mathrm{K}$ were applied to the slides for $25 \mathrm{~min}$ and they were washed in distilled water. Internal peroxidase activity was blocked by incubating the slides in $3 \% \mathrm{H}_{2} \mathrm{O}_{2}$ in absolute methanol for $5 \mathrm{~min}$. The slides were washed in PBS and incubated for an hour at $37^{\circ} \mathrm{C}$ in digoxigenin-containing solution labelled with deoxy-UTP and terminal deoxynucleotidyl transferase. Then the slides were washed in PBS and incubated for $30 \mathrm{~min}$ in a solution containing antidigoxigenin peroxidase. Washing again in PBS for $5 \mathrm{~min}$ was carried out, incubation in diaminobenzidine solution followed, and the last stage was counterstaining with methyl green.

Statistical analysis. Data on ROS activities (MDA level and SOD activity), the average numbers of cells undergoing apoptosis, necrosis, and p53 and caspase 3 expression were analysed using the Shapiro-Wilk and Levene tests for normality and homogeneity. Furthermore, data were subjected to a one-way ANOVA test, followed by the Duncan test. The statistical analysis was performed using Statistical Product and Service Solutions (SPSS, IBM, USA) version 25.0.

\section{Results}

Concerning ROS activity, the statistical analysis of MDA content indicated that CF exposure may trigger free radicals in the embryonic cerebral cortex, which was evidenced by a significant MDA increase in the $0.0417 \mathrm{mg} / \mathrm{kg}$ b.w. group compared to the control group. The statistical analysis of SOD activity proved that CF exposure triggered free radicals in the embryonic cerebral cortex, indicating a decrease in SOD activity in the 0.0417 and $0.0208 \mathrm{mg} / \mathrm{kg} \mathrm{b}$.w. dose groups to a level which was lower than that of the control group (Table 1).

Embryonic neuronal cell p53 expression is shown in Fig. 1. Neuronal cells manifesting p53 expression were indicated by a brownish colour while green indicated healthy cells. The image of p53-expressing cells in the control group was clearer than in the two insecticide-administered groups. Immunohistochemical examination indicated the cells expressing p53 had brown cytoplasm and the two $\mathrm{CF}$ groups expressed much more p53 than the control group (Fig. 1 and Table 1).

Embryonic neuron caspase 3 expression is depicted in Fig. 2. Neurons in which caspase 3 expression was evident are indicated by the colour black and healthy cells by pink. Caspase 3 expression in the control group was more clearly depicted than in the experimental groups. Neurons expressing caspase 3 were signified by blackish cytoplasm. There was a significant difference in caspase 3 expression between the $0.0208 \mathrm{mg} / \mathrm{kg}$ b.w. and $0.0417 \mathrm{mg} / \mathrm{kg}$ b.w. dose groups and the control group (Fig. 2 and Table 1).

Table 1. Results of MDA level, SOD activity, p53 and caspase 3 expression, and number of apoptotic and necrotic neuronal cells

\begin{tabular}{llll}
\hline Parameters & Control & $0.0208 \mathrm{mg} / \mathrm{kg} \mathrm{b} . \mathrm{w}$. of carbofuran & $0.0417 \mathrm{mg} / \mathrm{kg} \mathrm{b.w.} \mathrm{of} \mathrm{carbofuran}$ \\
\hline Malondialdehyde $(\mathrm{nm} / \mathrm{mg})$ & $23.63 \pm 10.56^{\mathrm{a}}$ & $28.26 \pm 10.33^{\mathrm{ab}}$ & $35.76 \pm 6.41^{\mathrm{b}}$ \\
\hline Superoxide dismutase activity (\%) & $59.91 \pm 18.46^{\mathrm{a}}$ & $35.77 \pm 4.31^{\mathrm{b}}$ & $34.23 \pm 6.91^{\mathrm{b}}$ \\
\hline p53 expression & $39.04 \pm 6.44^{\mathrm{a}}$ & $54.75 \pm 6.67^{\mathrm{b}}$ & $57.28 \pm 9.61^{\mathrm{b}}$ \\
\hline Caspase 3 expression & $25.44 \pm 2.74^{\mathrm{a}}$ & $40.08 \pm 6.68^{\mathrm{b}}$ & $44.13 \pm 7.21^{\mathrm{b}}$ \\
\hline Neuronal apoptotic cell & $49.13 \pm 7.02^{\mathrm{a}}$ & $64.15 \pm 8.08^{\mathrm{b}}$ & $71.60 \pm 7.83^{\mathrm{b}}$ \\
\hline Neuronal necrotic cell & $5.53 \pm 3.03^{\mathrm{a}}$ & $9.91 \pm 4.94^{\mathrm{ab}}$ & $13.27 \pm 7.87^{\mathrm{b}}$ \\
\hline
\end{tabular}

Values in a row for each parameter with different letters are significantly different from each other at $\mathrm{P}<0.05$ 

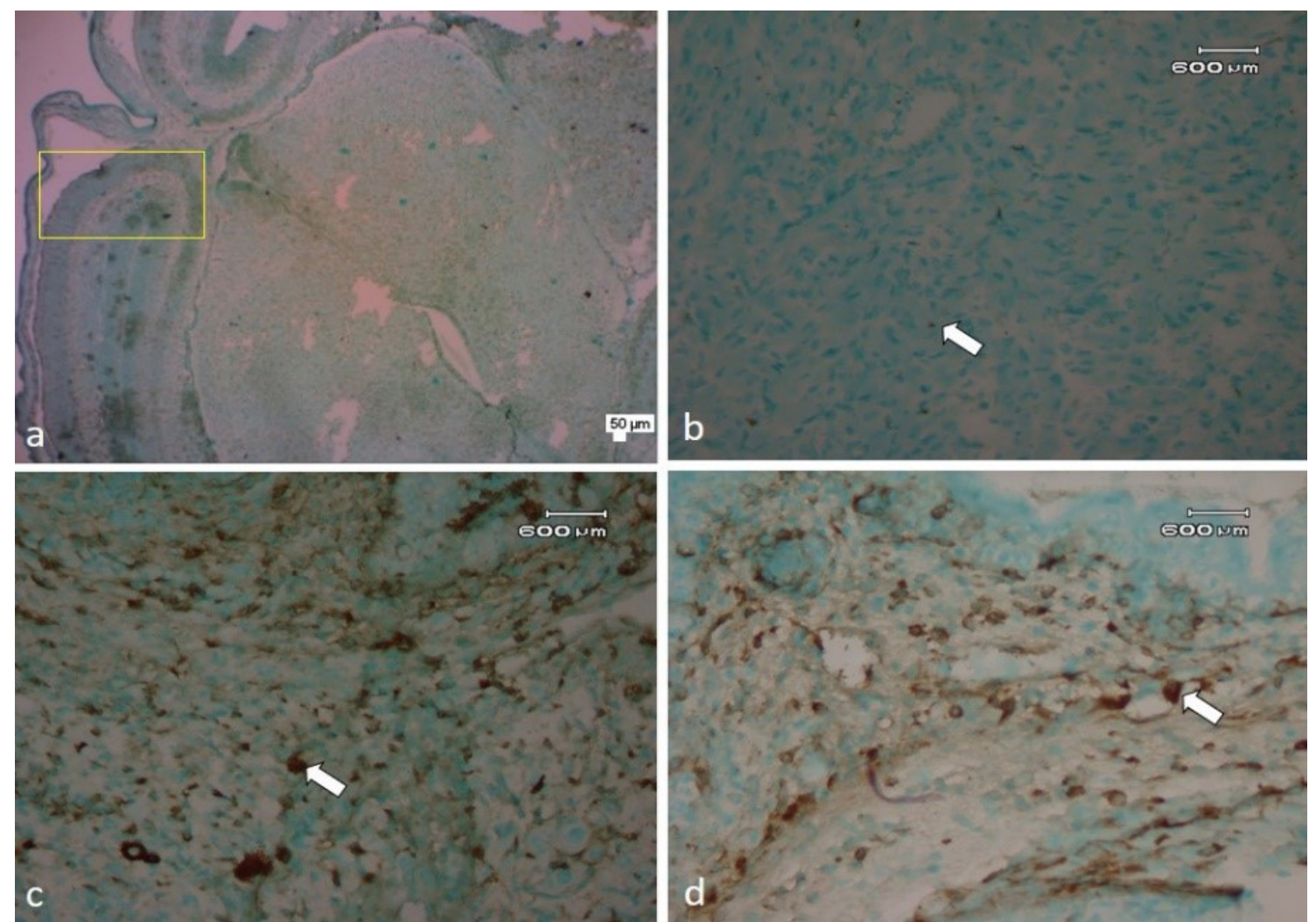

Fig. 1. Embryonic cerebral cortex neuron p53 expression in 6-15-day-old foetuses gestated by carbofuran-exposed mice (400×). Brown cells (marked by arrows) indicate p53-expressing neuronal cells

a - p53 expression in the embryonic cerebral cortex (yellow box), b - control group, c - lower-dose group ( $0.0208 \mathrm{mg} / \mathrm{kg}$ b.w.), $\mathrm{d}$ - higher-dose group $(0.0417 \mathrm{mg} / \mathrm{kg}$ b.w. $)$
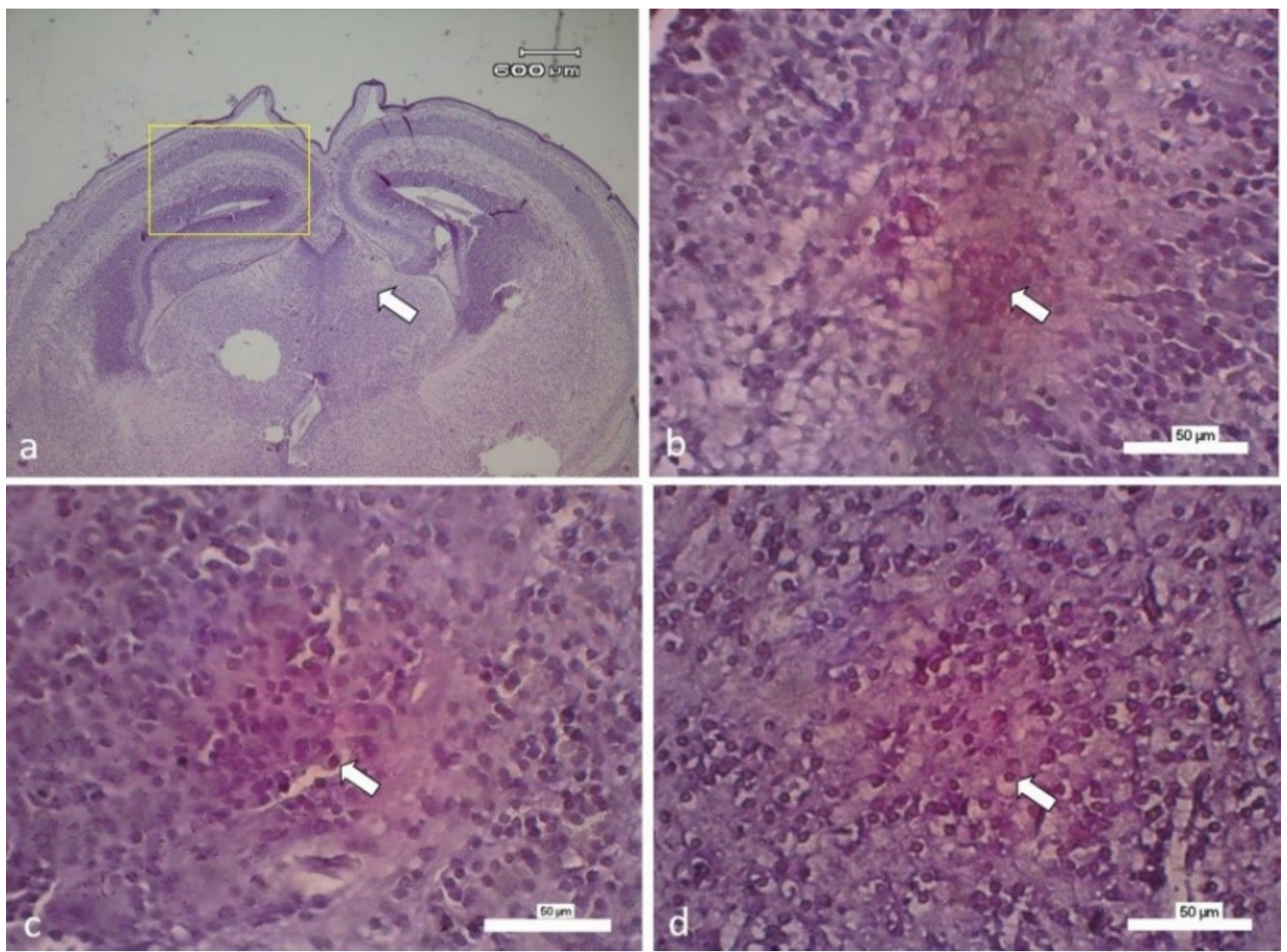

Fig. 2. Embryonic cerebral cortex neuronal cell caspase 3 expression examined in 6-15-day-old foetuses gestated by CF-exposed mice. Arrows mark neuronal cells expressing caspase 3

$\mathrm{a}$ - caspase 3 expression located in the embryonic cerebral cortex (yellow box), b - control group, c - lower-dose group (0.0208 $\mathrm{mg} / \mathrm{kg}$ b.w.), $\mathrm{d}$ - higher-dose group $(0.0417 \mathrm{mg} / \mathrm{kg}$ b.w. $)$ 

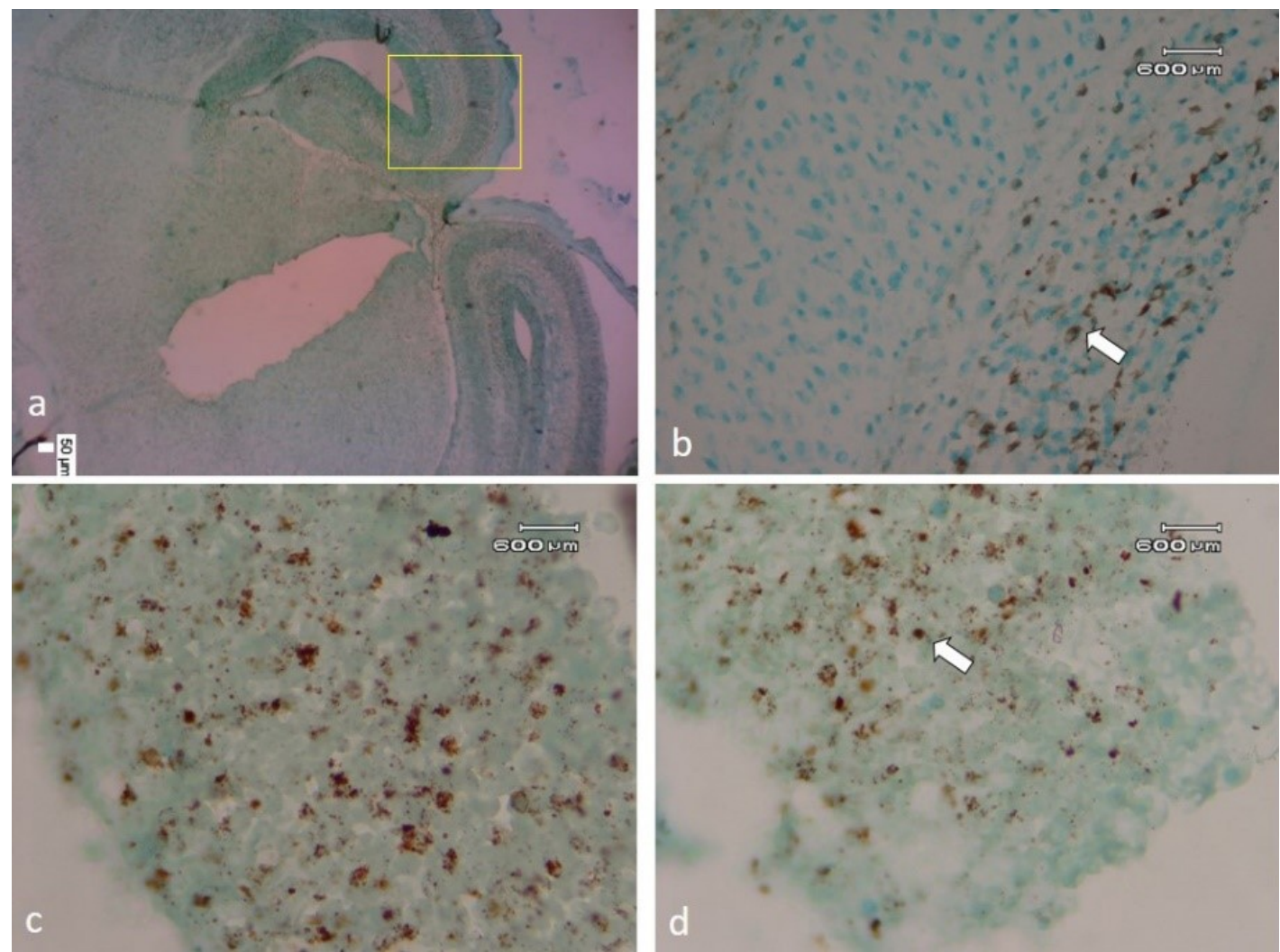

Fig. 3. Embryonic cerebral cortex neuron apoptosis examined in 6-15-day-old foetuses gestated by CF-exposed mice. Arrows mark apoptotic neurons (dark brownish cells)

$\mathrm{a}$ - apoptotic neurons located in the embryonic cerebral cortex (yellow box), $\mathrm{b}$ - control group, $\mathrm{c}$ - lower-dose group $(0.0208$ $\mathrm{mg} / \mathrm{kg}$ b.w.), $\mathrm{d}$ - higher-dose group $(0.0417 \mathrm{mg} / \mathrm{kg}$ b.w. $)$
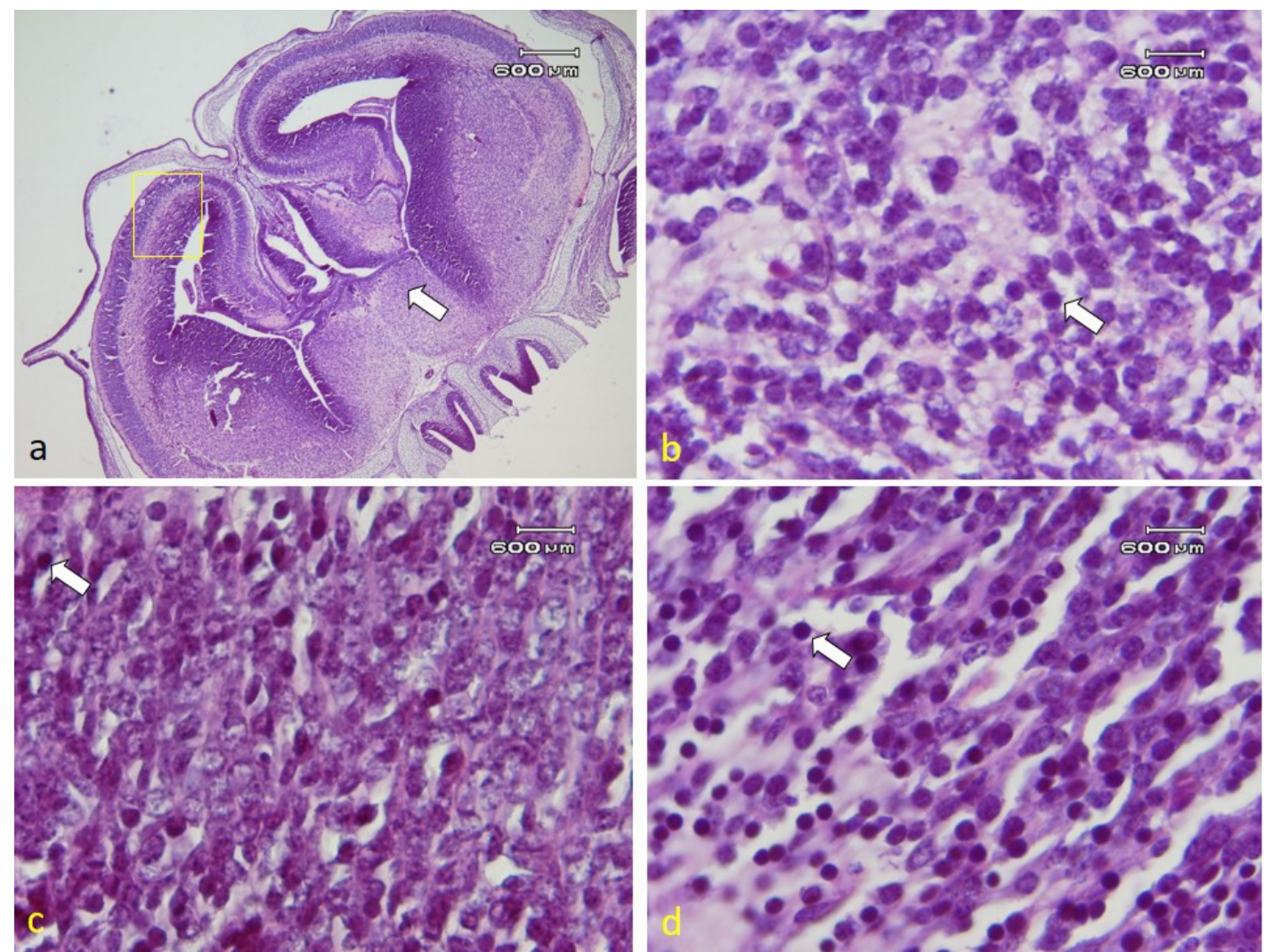

Fig. 4. Embryonic neuron necrosis in 6-15-day-old foetuses gestated by CF-exposed mice. Neurons undergoing necrosis (marked by arrows) are shrunken and have solid pyknotic nuclei and eosinophilic cytoplasm

$\mathrm{a}$ - necrotic neurons located in the embryonic cerebral cortex (yellow box), b - control group, c - lower-dose group (0.0208 $\mathrm{mg} / \mathrm{kg}$ b.w.), $\mathrm{d}$ - higher-dose group (0.0417 mg/kg b.w.) 
Apoptotic cells are presented in Fig. 3. Neurons succumbing to apoptosis have dark brownish cytoplasm (marked by arrows) and healthy cells are green. The demarcation of apoptotic cells in the control group was clearer than in the two groups which received the insecticide. A significant difference was noticed between the control and experimental groups, where the numbers of apoptotic cells after $0.0208 \mathrm{mg} / \mathrm{kg} \mathrm{b.w}$. and $0.0417 \mathrm{mg} / \mathrm{kg}$ b.w. CF exposure were much higher than those for the control group (Fig. 3 and Table 1).

Regarding necrotic cells, necrosis in the $0.0417 \mathrm{mg} / \mathrm{kg}$ b.w. CF-dosed group was distinct compared to the control group. Neurons undergoing necrosis showed pyknosis and karyorrhexis. There were significant differences between the control and experimental groups. More intense cellular necrosis was observed in the group administered $0.417 \mathrm{mg} / \mathrm{kg} \mathrm{b} . \mathrm{w}$. CF than in the control group (Fig. 4 and Table 1).

\section{Discussion}

CF was efficiently absorbed and distributed to various non-targeted organs through the mechanism of its action. The lipophilic property of carbamate enabled it to interact with serum lipid and tissue. The process of lipid peroxidation was initiated by hydrogen ions on the polyunsaturated fatty acid (PUFA) side chain, making the cell membrane interact with free radicals forming carbon radicals. Carbon radicals were oxidised forming peroxyl radicals, which bound the adjacent $\mathrm{H}^{+}$ions on the PUFA side chain. These are chain reactions which eventually discharge the PUFA chain into 9-hydroxynonenal, ethane, and pentane. The final product of lipid peroxidation was MDA, a high level of which indicated an oxidation process or cellular membrane destruction caused by free radicals (7).

Sub-acute oral exposure of male mice to CF for 28 days increased the MDA level as much as $43.70 \%$ (5). In the present research, it was found that exposure of 6-15-day-old gestating mice to CF increased the MDA level in their foetuses' brains. A significant increase in MDA by $51.38 \%$ was found in the group dosed at 0.0417 $\mathrm{mg} / \mathrm{kg}$ b.w. while exposure to a $0.0208 \mathrm{mg} / \mathrm{kg} \mathrm{b.w.} \mathrm{dose}$ did not cause any significant increase. High MDA content may cause oxidative stress in particular organs. A significant increase in ROS production was found in the higher-dose group. This finding indicated that the increase in neuron death caused by the toxicant was proportional to $\mathrm{CF}$ dosage exposure.

The role of the brain's defence system against antioxidant after chronic CF exposure is vital. The brain is very vulnerable to oxidative stress due to its high oxygen and polyunsaturated fat need, low antioxidant capacity, high volume reactive radical production, and large transitional metal content (such as iron) catalysing that reactive radical production (27). When tissue is threatened by oxidative stress it will be triggered to increase the activity and expression of antioxidant enzymes as a form of defence mechanism against free radicals. However the intensified antioxidant enzyme activity is not sufficient to reduce damage potentially caused by oxidative stress. Antioxidant enzyme expression is also triggered by growth factor stimulating tissue to survive (23). Enzymatic and non-enzymatic antioxidants are not evenly distributed in the brain regions, where the concentration of these substances varies.

In this research, the lower dosage $\mathrm{CF}$ exposure $(0.0208 \mathrm{mg} / \mathrm{kg}$ b.w.) significantly decreased SOD activity and the higher dosage $(0.0417 \mathrm{mg} / \mathrm{kg} \mathrm{b.w.})$ reduced it more significantly. This finding indicated that the higher $\mathrm{CF}$ dose may restrict SOD activity more significantly. The diminished SOD activity in CFexposed foetuses' brains indicated that the tissue had suffered oxidative stress, borne out by a higher MDA level. SOD is one of the enzymatic antioxidants of which the function is to neutralise superoxide free radicals $\left(\mathrm{O}_{2}^{+}\right)$to $\mathrm{H}_{2} \mathrm{O}_{2}$ and $\mathrm{O}_{2}$. Continuous free radical increase during $\mathrm{CF}$ exposure may increase intracellular enzyme consumption. This condition reduced antioxidant level and activity, as indicated by SOD activity in the experimental groups, which was significantly lower than in the control group.

Previous research proved that chronic oral $\mathrm{CF}$ exposure may drastically decrease adult mouse brain SOD activity (27). Similar research indicated SOD activity significantly declined in the liver and kidneys as the result of rising ROS production caused by $\mathrm{CF}$ exposure. Acute intraperitoneal $\mathrm{CF}$ exposure might heighten SOD activity. Increased SOD activity in CFexposed tissues indicated a defence/compensation mechanism activation which reduced excessive superoxide accumulation in the body (3).

Tumour suppression is the purpose of p53 protein; it is a redox-active transcription factor serving as a cellular response to genomic instabilities. A ROS activates p53 through DNA or chromosomal damage caused by hydroxyl radicals (10). When DNA damages $\mathrm{p} 53$, tumour suppressor genes will be accumulated to stop the cellular life cycle (in the $\mathrm{G}$ phase). The stopping of the cellular life cycle provides time for genomic recovery. In cases when the gene's condition cannot be recovered, p53 triggers apoptosis by increasing several $\mathrm{BCl}$ pro-apoptotic family transcriptions (specifically Bax protein). Bax protein suppresses $\mathrm{BCl}-2$ activity on the mitochondrial membrane by changing the membrane's permeability. Change in mitochondrial membrane permeability triggers cytochrome $\mathrm{C}$ release to cytosol, and cytochrome $\mathrm{C}$ activates Apaf-1 which in turn activates the caspase cascade (22).

In this research, it was found that $\mathrm{CF}$ exposure might improve embryonic cerebral cortex neuronal cell p53 protein expression in both insecticide-administered groups. This finding indicated that the higher the $\mathrm{CF}$ exposure, the more embryonic cerebral cortex neurons express p53 protein, despite the difference between the 
CF groups being insignificant. In the normal situation, p53 (wild-type p53) is maintained at a low level through degradation mediated by $\mathrm{Mdm} 2$ protein in the $\mathrm{N}$-terminal domain area. The concentration of p53 increases when there is DNA damage, chromosomal aberration, hypoxia, and/or telomere contraction (24).

Rapid increase and activation of p53 may be brought about by intracellular and extracellular stimuli (21). CF is one of the extracellular stimuli which damages neuron DNA. Protein p53 functions as a means of early detection of and response to the damage. This process was indicated by the significant increase of p53 expression in the two experimental groups compared to the control group. Expression of p53 differed insignificantly between the two dosed groups, indicating DNA damage caused by free radicals occasioned by CF. With the lower dose administered in our study, CF concentration has reached its limit to cause neuronal cell apoptosis. The concentration of CF triggered Bax/Bakdependent apoptosis, whereas higher doses caused mitochondrial permeability transition (MPT) leading to matrix swelling, outer membrane rupture, and release of apoptotic signalling molecules. If the concentration of the insecticide increases, p53 expression will not be upregulated and no more neuronal cells will suffer apoptosis. A low concentration of toxin exposure might cause autophagy or apoptosis while higher toxin concentration may cause cellular necrosis (19).

This research found that carbofuran insecticide also increased embryonic cerebral neuron caspase 3 protein expression in both groups which were given the preparation. It was indicated by the relationship whereby the higher the carbofuran exposure was, the greater the expression of caspase 3 protein by embryonic neurons was, despite the insignificant difference between the two amounts of insecticide administered. Caspase 3 expression mirrored p53 expression which correlated with the carbofuran concentration in the same way despite there being no significant difference between the lower- and higher-dosed groups, as previously stated. This finding concurred with one by other authors that hamster fibroblast pulmonary cell exposure to $\mathrm{N}$-nitrosocarbofuran increased caspase 3 concentration compared to that of a control group despite there being no significant difference among groups given the metabolite $(10 \mu \mathrm{M}, 30 \mu \mathrm{M}$, and $50 \mu \mathrm{M})(16)$.

Cells received a signal which was enough to activate caspase 3 to stimulate apoptosis. Cells which did not reach their caspase 3 limit would die slowly by an alternative mechanism. Caspase 3 has molecular weight of $32 \mathrm{kDa}$. This protein is the main caspase effector activated in almost all apoptosis processes. Direct or indirect caspase 3 activation affected target protein decomposition and specific DNA decomposition causing specific morphological changes in apoptosis cells. When caspase 3 was activated the cells were in "committed to death" status and apoptosis, an irreversible condition at that point, was inevitable. Active cellular caspase 3 expression occurred during the initial phase of the apoptosis process initiating morphological changes leading towards classical cell death. Hence, caspase 3 expression improvement detection may serve as a foundation for detecting cellular apoptosis (28).

Apoptosis normally happens as a homeostatic mechanism to maintain the cell population in tissue during developmental or aging processes. It also takes place as a defence mechanism when the immune system destroys cells damaged by diseases or harmful agents. Apoptosis is curtailable and the process stops when dead cells have been removed with the caspase which those cells activated. Apoptosis cell removal and absorption by macrophages was not merely removing cell remnants. Specific caspase from the dead cells is involved in apoptosis. The process can be visualised by detecting DNA degradation, which itself (being mostly nucleosomal) can be detected using agarose gel electrophoresis or the in situ TUNEL technique (15).

The massive apoptosis of neurons at both doses indicated that $\mathrm{CF}$ was the trigger to increase ROS activity. Hydroxyl radicals damaged DNA, which upregulated p53 and caspase 3 expression triggering cellular apoptosis. The significant increase in caspase 3 and p53 in the experimental groups compared to the control group and insignificant increases in both experimental groups suggested that CF exposure did not stimulate embryonic cerebral cortex recovery. Different authors' results were higher p53 protein expression upregulation compared to that for cell apoptosis caused by radiation during mouse brain development, which indicated recovery in the cortical part (2). The embryonic central nervous system (CNS) possesses great ability to recover from injury. If the embryonic brain is damaged, most of its structure will remain unchanged after the birth of the individual although several aberrations can still be detected. This ability is absent in the adult brain because this injury recovery process requires microglia and astrocyte activation. This process indicated that cell death mechanism was the result of interrelation of these components. During the repair period, amoeboid microglia infiltrate the brain and ingest the apoptotic cells. These microglial cells are positive for multiple microglial markers, and mRNAs for the microglia-related cytokines tumour necrosis factor alpha, interleukin-1 $\beta$ and macrophage colony stimulating factor are upregulated. The upregulation is of genes relevant to glial cells, inflammation, the extracellular matrix, glycolysis, proliferation and neural development. The developing brain has the capacity to respond to the damage induced by extrinsic chemical stresses, including changing the expression of numerous genes and the induction of microglia to aid the repair process (29).

The vulnerability of the developing brain is in the possibility for agents/active metabolites to reach neurons in the exposure period. Exposure happening before or after the organs (i.e. brains) are well-developed would find these organs less vulnerable to inhibition 
compared to exposure happening during the developmental phase of these organs. The adult brain is shielded by the blood-brain barrier (BBB) protecting the brain from chemicals. Embryonic and infant brains up to 6 months of age are not fully protected by the BBB (1). A statistical analysis of average apoptotic cell numbers suggested that CF exposure was able to trigger free radicals in the embryonic brain. Hydroxyl radicals resulting from $\mathrm{CF}$ exposure might damage DNA and stimulate p53 expression, correlating with caspase 3 expression and cell apoptosis.

A statistical analysis of the average number of necrotic cells suggested that $\mathrm{CF}$ exposure may trigger free radicals in the embryonic brain, as evidenced by the larger MDA content in the experimental groups compared to the control group. Higher MDA content signified cellular membrane damage which caused necrosis. It was reported (11) that the lipophilic feature of CF may mitigate oxidative stress and damage in membrane structure and function. Moreover, damage to the lipid membrane also may increase lipid peroxide in a synaptic membrane which is chronically exposed to $\mathrm{CF}$. Lipid membrane damage is a form of CF interaction with cellular membranes.

Necrotic cell injury was mediated by two main mechanisms, namely energy supply inhibition and cellular membrane damage. Morphological changes caused by necrosis were most notably the following: cell swelling, cytoplasm vacuoles, endoplasmatic reticulum swelling, cytoplasm blebs, mitochondria swelling, ribosome disaggregation which damages the organelle membrane, lysosome swelling, and cellular membrane rupture. Cell deaths caused by cytoplasm inflammation and karyolysis and lysis of nuclei were classified as necrosis. In some cases, some stress types, such as thermal shock, hypoxia, and lower doses of anticancer drugs might induce apoptosis. However, at greater intensity or higher dose, these stressors might cause necrosis. Lower intensity of stimuli might cause apoptosis while reduced energy and caspase activation might also cause necrosis (17).

In this research, it was proven that $\mathrm{CF}$ potentiated embryonic neuron necrosis in the experimental groups compared to the control group. The higher the CF exposure, the more embryonic cerebral cortex neurons underwent necrosis. The number of embryonic cerebral cortex cells dying by necrosis was smaller than the number of cells dying by apoptosis. During the neurogenesis phase, most of the cells were terminated by physiological apoptosis as homeostatic action. However, the proportional rise in necrotic cell deaths was higher than that in apoptotic cell deaths (the number of cells eliminated by apoptosis increased by $45.74 \%$ while the number of cells eliminated by necrosis increased by $139.96 \%$ ). The number of neurons undergoing necrosis caused by $\mathrm{CF}$ was higher day by day and reached its peak at the culmination of neurogenesis (the $14^{\text {th }}-17^{\text {th }}$ days), as much as $580.17 \%$ of the typical neurogenic period level after administration of $0.0208 \mathrm{mg} / \mathrm{kg} \mathrm{b.w}$. and
$662.64 \%$ after administration of $0.0417 \mathrm{mg} / \mathrm{kg} \mathrm{b.w.} \mathrm{of}$ $\mathrm{CF}$. The developing brain is particularly vulnerable to environmental toxins. Growing cells are more vulnerable to toxins at the culmination of neurogenesis, and neuron deaths with toxin aetiology during this time are many more than during the than organogenesis period (30).

The total embryonic cerebral cortex neuron deaths (apoptotic and necrotic) caused by $\mathrm{CF}$ exposure increased by $35.51 \%$ for the dose of $0.0208 \mathrm{mg} / \mathrm{kg} \mathrm{b.w}$. and by $55.27 \%$ for $0.0417 \mathrm{mg} / \mathrm{kg}$ b.w. These percentages exceeded the normal embryonic neuron death rate by $10 \%$. Based on this finding, it can be predicted that these individuals would not demonstrate full neural function after birth. Several attempts to prevent ROS activity and to reduce neuron death caused by $\mathrm{CF}$ exposure might be made. Antioxidant intake (such as allopurinol) during pregnancy might reduce oxidative stress by inhibiting the free radical scavenger effect. Erythropoetin, an antiapoptosis cytokine and tissue protector, was effective in preventing neural damage in experimental animals (5).

$\mathrm{CF}$ exposure during the embryonic phase might trigger intrinsic ROS generation to initiate oxidative damage. The existence of sub-acute ROS decreased SOD and increased MDA levels. The existence of ROS also caused embryonic neuronal cell DNA damage, evidenced by stronger p53 and caspase 3 expression which in turn triggered cellular apoptosis. Escalating caspase 3, p53, and embryonic neuronal cell apoptosis was found after the $0.0208 \mathrm{mg} / \mathrm{kg}$ b.w. dose administration.

Conflict of Interests Statement: The authors declare that there is no conflict of interests regarding the publication of this article.

Financial Disclosure Statement: The present article was part of a Ph.D, for funding the research for which the authors express sincere thanks to the Ministry of Research, Technology, and Higher Education of the Republic of Indonesia.

Animal Rights Statement: The study was approved by the Faculty of Veterinary Medicine Animal Ethics Committee of Universitas Airlangga. All variables were considered in accordance with the Ethics Committee related to the animal handling to ensure no discomfort or pain was caused to the animals during sampling (certificate registration number: 2011/111-KE).

Acknowledgments: The authors express sincere thanks to the Director of Postgraduate Studies at Universitas Airlangga and the Dean of the Faculty of Veterinary Medicine for providing all necessary facilities and funds for conducting research work. 


\section{References}

1. Anna K., Bal-Price J., Helena T.H.: Effects of pesticides on neuronal and glial cell differentiation and maturation in primary cultures. In: Pesticides - The impacts of pesticide exposure. Edited by M. Stoytcheva, InTech, London, 2011, pp. 341-356.

2. Bolaris S., Bozas E., Benekou A., Phillippiis H., Stylianopoulou F.: In utero radiation-induced apoptosis and $\mathrm{p} 53$ gene expression in the developing rat brain. Int J Radiat Biol 2001, 77, 71-81.

3. Chandra D., Tripathi U.N., Srivastava S., Swaroop A.: Carbofuran induced biochemical toxicity in mice: Protective role of Momordica charantia. Euro J Exp Bio 2011, 1, 106-112.

4. Conti M., Morand P.C., Levillain P., Lemonnier A.: Improved fluorometric determination of malonaldehyde. Clin Chem 1991, 37, 1273-125.

5. Ghezi P., Brines M.: Erythropoietin as an antiapoptotic, tissueprotective cytokine. Cell Death Differ 2004, 11 Suppl 1, 37-44.

6. Gupta V.K., Pathak A., Siddiqi N.J., Sharma B.: Carbofuran modulating functions of acetylcholinesterase from rat brain in vitro. Adv Biol 2016, Article ID 3760967. http://dx.doi.org/10.1155/2016/3760967.

7. Haggag M.E.Y.E., Elsanhoty R.M., Ramadan M.F.: Impact of dietary oils and fats on lipid peroxidation in liver and blood of albino rats. Asian Pac J Trop Biomed 2014, 4, 52-58.

8. Handal A.J., Lozoff B., Breih J., Harlow S.D.: Effect of community of residence on neurobehavioral development in infants and young children in a flower-growing region of Ecuador. Environ Health Perspect 2007, 115, 128-133.

9. Ighodaro O.M., Akinloye O.A.: First line defence antioxidantssuperoxide dismutase (SOD), catalase (CAT), and glutathione peroxidase (GPX): their fundamental role in the entire antioxidant defence grid. Alexandria Med 2018, 54, 4, 287-293.

10. Jaganathan S.K., Mandal M.: Involvement of non-protein thiols, mitochondrial dysfunction, reactive oxygen species, and p53 in honey-induced apoptosis. Invest New Drugs 2010, 28, 624-633.

11. Kamboj A., Kiran R., Sandhir R.: Carbofuran-induced neurochemical and neurobehavioral alterations in rats: attenuation by $N$-acetylcysteine. Exp Brain Res 2006, 170, 567-575.

12. Kamboj S.S., Kumar V., Kamboj, A., Sandhir R.: Mitochondrial oxidative stress and dysfunction in rat brain induced by carbofuran exposure. Cell Mol Neurobiol 2008, 28, 961-969.

13. Kim S.J., Kim J.E., Ko B.H., Moon I.S.: Carbofuran induces apoptosis of rat cortical neurons and down-regulates surface $\alpha 7$ subunit of acetylcholine receptors. Mol Cells 2004, 17, 242-247.

14. Kłys M., Kosuń J., Pach J., Kameńczak A.: Carbofuran poisoning of pregnant woman and fetus per ingestion. J Forensic Sci 1989, 34, 1413-1416.

15. Kyrylkova K., Kyryachenko S., Leid M., Kioussi C.: Detection of apoptosis by TUNEL assay. Methods Mol Biol 2012, 887, 41-47.
16. Lee B.L., Oh S.H., Chung J.H., Moon C.K., Lee B.H.: N-Nitroso metabolite of carbofuran induces apoptosis in CHL cells by cytochrome-mediated activation of caspases. Toxicology 2004, 201, 51-58.

17. Martin L.J.: Mitochondrial and cell death mechanisms in neurodegenerative diseases. Pharmaceuticals (Basel) 2010, 3, 839-915.

18. Masoud A., Sandhir R.: Increased oxidative stress is associated with the development of organophosphate-induced delayed neuropathy. Hum Exp Toxicol 2012, 31, 1214-1227.

19. Orrenius S., Nicotera P., Zhivotovsky B.: Cell death mechanisms and their implications in toxicology. Toxicol Sci 2011, 119, 3-19.

20. Otieno P.O., Lalah J.O., Virani M., Jondiko I.O., Schramm K.W.: Carbofuran and its toxic metabolites provide forensic evidence for furadan exposure in vulture (Gyps africanus) in Kenya. Bull Environ Contam Toxicol 2010, 84, 536-544.

21. Paxinos G., Halliday G., Watson C., Koutcherov Y., Wang H.Q.: Atlas of the developing mouse brain. Elsevier. Melbourne, 2007, p. 48.

22. Pistritto G., Trisciuoglio D., Ceci C., Garufi A., Gabriella D.G.: Apoptosis as anticancer mechanism: function and dysfunction of its modulators and targeted therapeutic strategies. Aging 2016, 8, 603-619.

23. Poljsak B., Šuput D., Milisav I.: Achieving the balance between ROS and antioxidants: When to use the synthetic antioxidants. Oxid Med Cell Longev 2013, Article ID 956792. http://dx.doi.org/10.1155/2013/956792.

24. Ponnuswamy A., Fahraeus R.: The regulation of p53 synthesis. Klin Onkol 2012, 25, 2s32-2s37.

25. Rai D.K., Sharma B.: Carbofuran-induced oxidative stress in mammalian brain. Mol Biotechnol 2007, 37, 66-71.

26. Redza-Dutordoir M., Averill-Bates D.A.: Activation of apoptosis signalling pathways by reactive oxygen species. Biochim Biophys Acta 2016, 1863, 2977-2992.

27. Salim S.: Oxidative stress and the central nervous system. J Pharmacol Exp Ther 2017, 360, 201-205.

28. Sanchez-Torres L., Vargas F.D.: Apoptosis: the phenomenon and its determination. Tec Pecu Mex 2003, 41, 49-62.

29. Ueno M., Katayama K., Yamauchi H., Yasoshima A., Nakayama H., Doi K.: Repair process of fetal brain after 5-azacytidine-induced damage. Eur J Neurosci 2006, 24, 2758-2768.

30. Widjiati, Luqman E.M.: The critical period and type of cell death in the embryonal brain development caused by carbofuran exposure to detect a decreasing in the reflex and motoric function on infant mice (Mus musculus). Laporan Penelitian Riset Unggulan Perguruan Tinggi. Lembaga Penelitian dan Pengabdian Kepada Masyarakat. Surabaya. 2012. 